This document is published in:

Computers \& Education, (2013), 68, 586-596.

DOI: http://dx.doi.org/10.1016/j.compedu.2012.03.002

(C) 2012 Elsevier Ltd. 


\title{
Impact of an augmented reality system on students' motivation for a visual art course
}

\author{
Ángela Di Serio ${ }^{a}$, María Blanca Ibáñez ${ }^{\mathrm{b}, *}$, Carlos Delgado Kloos ${ }^{\mathrm{b}}$ \\ a Departamento de Computación y Tecnología de la Información, Universidad Simón Bolívar, Caracas, Venezuela \\ b Departamento de Ingeniería Telemática, Universidad Carlos III de Madrid, Av. de la Universidad, 30, 28911 Leganés, Madrid, Spain \\ *Corresponding author. Tel.: +34 91624 8744; fax: +34 916248749. \\ E-mail addresses: adiserio@ldc.usb.ve (Á. Di Serio), mbibanez@it.uc3m.es (M.B. Ibáñez), cdk@it.uc3m.es (C.D. Kloos).
}

\begin{abstract}
In this paper, the authors show that augmented reality technology has a positive impact on the moti-vation of middle-school students. The Instructional Materials Motivation Survey (IMMS) (Keller, 2010) based on the ARCS motivation model (Keller, 1987a) was used to gather information; it considers four motivational factors: attention, relevance, confidence, and satisfaction. Motivational factors of attention and satisfaction in an augmentedreality-based learning environment were better rated than those obtained in a slides-based learning environment. When the impact of the augmented reality system was analyzed in isolation, the attention and confidence factors were the best rated. The usability study showed that although this technology is not mature enough to be used massively in education, enthu-siasm of middle-school students diminished most of the barriers found.
\end{abstract}

Keywords: Augmented reality, Motivation, Middle-school education

\section{Introduction}

Scientists, researchers, and teachers agree that students who are motivated to learn are more likely to engage, persist, and expend effort for task completion than those who are unmotivated (Csikszentmihalyi, 1991; Efklides, Kuhl, \& Sorrentino, 2001; Keller, 1979; Schmidt, 2007). Although there is no consensus about how to define motivation (Kleinginna \& Kleinginna, 1981), researches at the education field usually adopt the definition stated by Houssaye (cited by Vianin, 2006, p. 24) that describes motivation as the force that initiates and directs behavior. Thus, it can be stated that "motivation provides a source of energy that is responsible for why learners decide to make an effort, how long they are willing to sustain an activity, how hard they are going to pursue it, and how connected they feel to the activity." (Rost, 2010).

Research on education has always been very active defining specific actions that teachers should take to increase motivation in classrooms (Huitt, 2011; Keller, 1987a,b; Raffini, 1993; Stipek, 1998; Taran, 2005; Wlodkowski, 1978). In the past few years, there have been considerable efforts in the use of technology to support and enhance learning. Learning environments have integrated, among others, the use of computers, multimedia material, whiteboards, internet, Web 2.0 authoring tools, simulations, games and more recently mobile phones and immersive technologies such as 3D virtual worlds and augmented reality (Dror, 2008). Although learning is a holistic process and "... it cannot be understood by simply analyzing human responses to attributes of technologies that carry the messages to be learned" (Jonassen, 1994), several empirical evaluations analyzing the effects of particular technologies on educational practices yield encouraging results. Indeed, technologies with different affordances have been identified as one of the factors that might improve student motivation. Earlier studies carried out on learning environments that are not web-based found that technology causes positive attitudes and higher motivation toward instruction (Kulik, 1994; Schacter, 1999; Sivin-Kachala, 1998). The integration of web tools in learning activities marked an important turning point. Indeed, several studies proved that motivation is enhanced by the sense of control and the possibility to create knowledge collaboratively that offer web technologies (Annetta, Minogue, Holmes, \& Cheng, 2009; Bolliger, Supanakorn, \& Boggs, 2010; Rovai, Ponton, Wighting, \& Baker, 2007). 3D virtual worlds can be considered an evolution of WWW, they have been successfully employed in educational applications (Chittaro \& Ranon, 2007; Dalgarno \& Lee, 2010) and some studies reveal that their immersive and interactive capabilities foster student motivation and engagement (Barab, Thomas, Dodge, Carteaux \& Tuzum, 2005; Huang, Rauch, \& Liaw, 2010; Shen \& Eder, 2009).

Advances in mobile technology make it nowadays feasible to use augmented reality (AR) technology for learning (Specht, Ternier, \& Greller, 2011). This technology makes the enhancement of our senses (vision, aural, and tactile) with virtual or naturally invisible information superimposed on top of the real world by digital means possible (Azuma, 1997). Augmented reality, much like 3D virtual worlds, offers different degrees of immersion and interaction that might help to engage students in learning activities. There have been some attempts to use AR for training and educational purposes (Billinghurst, Kato, \& Poupyrew, 2001; Nejdl, Tochtermann, Bogen, Wind, \& Giuliano, 2006; Platonov, Heibel, Meier, \& Grollmann, 2006). However, the potential of AR in education remains unexplored and, there is a limited amount of studies investigating student motivation with the use of AR. In this paper, we explore the impact of augmented reality technology on the motivation of middle-school students. 


\section{Literature review}

\subsection{Augmented reality and its use in learning}

The term augmented reality refers to technology that enhances the user's sensory perception of the real world with a computer-assisted contextual layer of information (Azuma, 1997). Augmented reality (AR) and virtual reality (VR) are closely related; both are contained within the Milgram Reality-Virtuality Continuum (Milgram \& Kishino, 1994) and reflect different levels of user's immersion in environments where physical and digital objects co-exist. VR technology completely replaces a real environment with a synthetic environment, whereas AR brings virtual information to the user context (Azuma, 1997). According to R. Azuma et al. (Azuma et al., 2001), AR systems are characterized by three properties:

(1) Combine real and virtual objects in a real environment.

(2) Align real and virtual objects with each other.

(3) Run interactively, and in real time.

Augmented reality and virtual reality share some common features such as immersion, navigation and interaction (Dunleavy, Dede, \& Mitchell, 2009; Kye \& Kim, 2008). These features can be derived from Azuma's AR properties.

According to Sherman and Craig (Sherman \& Craig, 2003), immersion encompasses both the physical aspects of the environment (Lombard \& Ditton, 1997) and the condition whereby people are absorbed by an activity (Csikszentmihalyi, 1991). Display and tracking technologies deal with the three AR properties and contribute to physical immersion showing changes in the environment as result of movement or interaction. The use of different display and tracking technologies might cause different degrees of physical immersion. For instance, head mounted or spatial displays foster a higher degree of immersion than handheld displays such as PDAs or smart phones (Carmigniani et al., 2010; Krevelen \& Poelman, 2010). Furthermore, poor alignment of digital information with real objects would cause a loss of immersion feeling. An educator's challenge is to use physical immerse capabilities of AR technology to foster student engagement in learning activities.

Azuma's second property implies that digital information is superimposed on the real environment for the user's perspective. As result, the users point of view changes and they require knowing where they are, where everything is and how to get particular objects or places, that is the navigation process. Although navigation is not the main objective of a user in a virtual or augmented environment, it has direct implications on the way users interact with the pervasive computing landscape (Burigat \& Chittaro, 2007; Kye \& Kim, 2008; Narzt et al., 2005) and also contributes to the feeling of immersion (Huang et al., 2010).

Azuma's third AR property is directly related with real-time interactivity. AR technology naturally supports one of the three types of interaction needed in education stated by M. Moore (Moore, 1989): learner-content interaction. Several authors emphasize the importance of this kind of interaction to foster cognitive tasks such as understanding, memory, and imagination among others (Dalgarno, 2004; Neumann \& Majoros, 1998). The quality of learner-content interaction is tied to the kind of AR interface used and goes from simple WIMP interfaces (windows, icons, menus, and pointing) to haptic devices (Carmigniani et al., 2010; Krevelen \& Poelman, 2010). The other two types of interactions: learner-instructor and learner-learner should be supported by the environment itself and are tied to collaboration (Chittaro \& Ranon, 2007; Dalgarno \& Lee, 2010).

Educators and researchers are enthusiastic about the use of emerging technologies such as augmented reality and multi-user virtual environments in teaching and learning (Bower, 2008; Dalgarno \& Lee, 2010; Dunleavy et al., 2009; Kye \& Kim, 2008). The immersion, interaction and navigation features of these technologies are expected to improve student satisfaction, help in knowledge comprehension and are potentially useful in learning tasks that require experimentation; spatial ability; and collaboration among others (Dalgarno \& Lee, 2010; Dunleavy et al., 2009). Furthermore, some authors highlight unique affordances of AR such as its capacity to promote kinesthetic learning tasks and its support for memory cognitive processes (Chien, Chen, \& Jeng, 2010; Dunleavy et al., 2009). On the other hand, recent advances in mobile technology and integration of AR software in PCs encourage the use of AR in education. There are indeed some initial attempts to use AR for learning tasks with these simple devices. Table 1 presents some AR applications recently developed in education and identify the AR learning affordances they have exploited. Our study analyzes the impact of a basic AR system on middle-school students' motivation to learn a visual art module. The system is composed of PCs, webcams and markerless images which are easily available in schools but with limited capabilities of immersion, interaction and navigation.

\subsection{Student motivation}

In the educational arena, motivation can be defined as the student's desire to engage in a learning environment (Keller \& Litchfield, 2002). The impact of motivation on students' academic achievements and learning outcomes has been addressed in several studies. P. Pintrick (Pintrich, 1999) highlights the role of motivation in promoting and sustaining self-regulated learning tied to better academic performance (Zimmerman, Bandura, \& Martinez-Pons, 1992). His study proves that three general types of motivational beliefs: self-efficacy, task-value and goal orientation predict self-regulation. Also D. Schunk (cited by Schmidt, 2007, p. 44) states that motivation has potential to 
Table 1

A summary of AR applications in education.

\begin{tabular}{|c|c|c|c|}
\hline Research & AR technology employed & Most relevant features & Learning affordances \\
\hline Dünser, Steinbügl, Kaufmann, and Glück (2006) & $\begin{array}{l}\text { HMD. } \\
\text { Stylus tracked with 6Do. }\end{array}$ & $\begin{array}{l}\text { Immersion. } \\
\text { Interaction. }\end{array}$ & $\begin{array}{l}\text { Spatial ability. } \\
\text { Collaboration. } \\
\text { Motivation. }\end{array}$ \\
\hline Gutiérrez et al. (2010) & Fiducial markers. PC. webcam & $\begin{array}{l}\text { Interaction. } \\
\text { Navigation. }\end{array}$ & Spatial ability. \\
\hline Maier, Tönnis, and Klinker (2009) & Fiducial markers. PC. webcam & $\begin{array}{l}\text { Interaction. } \\
\text { Navigation. }\end{array}$ & $\begin{array}{l}\text { Experiential learning. } \\
\text { Spatial ability. }\end{array}$ \\
\hline Klopfer and Squire (2008) & Handheld devices. & $\begin{array}{l}\text { Navigation. } \\
\text { Immersion. }\end{array}$ & $\begin{array}{l}\text { Collaboration. } \\
\text { Motivation. }\end{array}$ \\
\hline Nilsson, Johansson, and Jönsson (2010) & $\begin{array}{l}\text { HMD. } \\
\text { Marker Tracking. }\end{array}$ & $\begin{array}{l}\text { Immersion. } \\
\text { Navigation. }\end{array}$ & Collaboration. \\
\hline Chien et al. (2010) & Fiducial markers. PC. webcam & $\begin{array}{l}\text { Interaction. } \\
\text { Navigation. }\end{array}$ & $\begin{array}{l}\text { Spatial ability. } \\
\text { Support to memory cognitive processes. }\end{array}$ \\
\hline Henderson et al. (2011) & $\begin{array}{l}\text { Custom-built stereo VST HWD. } \\
10 \text { tracking cameras. }\end{array}$ & $\begin{array}{l}\text { Immersion. } \\
\text { Navigation. } \\
\text { Interaction. }\end{array}$ & Experiential learning. Kinesthetic learning. \\
\hline Sumadio et al. (2010) & Fiducial markers. PC. webcam & $\begin{array}{l}\text { Navigation. } \\
\text { Interaction. }\end{array}$ & Experiential learning. Motivation. \\
\hline
\end{tabular}

influence the what, when, and how of learning, and increases the likelihood of engaging in activities that will help students to learn and achieve better performance. Thus, learning strategies that connect with students' interests and provide them with opportunities to take an active part in their instruction can lead to increased engagement, effort, and eventual success (Theall, 1999b). The opposite thesis is also true; lack of motivation can be a major obstacle that prevents learner success (Jeamu, Kim, \& Lee, 2008).

A learning motivation theory defines the set of factors which influence students' motivation to learn. A study of M. Theall (Theall, 1999b) compiles in an "author by factor matrix" the motivational factors present in thirteen motivation theories. The matrix includes relevant theories such as P. Pintrich's work on self-regulation based on an expectancy-value model of motivation (Pintrich \& De Groot, 1990), Perry's work on perceived control and attributional issues (Perry, 1991) (cited by Theall, 1999a, p. 8) and Keller's work based on the ARCS model (Keller, 1987a). The theories surveyed have six consensual motivation factors: inclusion, attitude, meaning, competence, leadership and satisfaction. These motivation factors can be seen as building blocks for instructional strategies that intend to provide reinforcement for activities to be encouraged; set challenging yet attainable goals for learning; provide feedback on progress; enhance the perceived value of the tasks, convince the learners they can succeed; give the learners choices about goals and strategies for achieving them (Svinicki, 1999).

A. Barger and K. Byrd (Barger \& Byrd, 2011) state that computer-based instructional design would benefit from the application of Keller's ARCS model and Maslow's theory of needs. J. Keller proposes a problem-solving approach to applying motivation to instructional design called ARCS, which is directly based on four out of six components reported at M. Theall's survey: Attention, Relevance, Confidence and Satisfaction (Keller, 1987a,b). The missing factors in ARCS, inclusion and leadership, can be derived from the treatment given by Keller's model to the other four factors (Theall, 1999b). Keller's model illustrates a motivational design process where the first step is to gain and sustain learners' attention and stimulate their curiosity to learn. The second step must guarantee that learning activities have been aligned with learners' personal goals and needs in order to be perceived as relevant. According to the model, learners should build confidence by feeling in control and having expectancy for success because the degree of expectancy achieved will determine the amount of effort learners invest to accomplish the activities. Goal-directed effort will also be influenced by external factors such as teacher enthusiasm, social values, quality of instruction and availability of resources (Keller, 2008). The learners' effort combined with their knowledge, ability and skills will lead to the accomplishment of the learners' activities with some degree of performance. Finally, the cognitive evaluation and the reflection learners made on their performance determine their levels of satisfaction. Adequate levels of satisfaction help them to maintain motivation (Rodgers \& Withrow-Thorton, 2005). Thus, each ARCS model component plays a critical role in motivating students throughout the learning process.

On the other hand, a diagnostic evaluation of student motivation is necessary to determine the strengths and weaknesses of instructional design used. In this sense, the ARCS model was originally developed as a descriptive model for diagnosing problems associated with learning motivation (Driscoll, 2000, p. 3-28) as cited in (Huang, Diefes-Dux, Imbrie, Daku, \& Kallimani, 2004). The Instructional Materials Motivation Survey (IMMS) was the instrument developed to measure learner motivation following the ARCS model (Keller, 2010). The instrument is particularly relevant for our study because it has been validated and used on several research studies using technology as a motivational factor in learning (Bolliger et al., 2010; Green \& Sulbaran, 2006; Huang et al., 2004; Rodgers \& Withrow-Thorton, 2005).

In this work, we use IMMS to evaluate motivation levels of middle-school students towards a visual art course. The course was taught using two different learning scenarios, the first one was slides-based, and the second one used augmented reality technology.

\section{Case study}

The study was conducted on three sections of a visual art compulsory course taught at a middle school in Madrid (Spain). The experiment was performed on a two-sessions-module on Italian Renaissance Art. The module material comprised images and information related to eight relevant masterpieces of Italian Renaissance prepared by the teacher of the school. Students were expected to acquire both general information about the masterpieces studied and guidelines to appreciate the art work of the Renaissance.

In order to inflict the minimum disturbance upon the course, the design and the content of previous editions were kept intact. The sessions should maintain a general structure: study of four Renaissance art masterpieces through the presentation of their images and explanation of their relevant details. Whereas the first session maintained a teaching scenario using slides (TS1), the education scenario of the second session (TS2) was changed to one supported by augmented reality technology. 
TS1 comprised the study of four masterpieces of Italian Renaissance Art using images illustrating the whole pieces and some of their relevant details. Students received the lecture in a room where their chairs were arranged in auditorium style seating. There was a small presentation area for the teacher and all the room lights were off. The masterpieces studied were: "David" (Michelangelo, 1504), "St. John the Baptist" (Leonardo Da Vinci, 1513), The Dome of St. Peter's Basilica (Bramante, 1506) and The School of Athens (Raphael, 1510).

The masterpieces studied included in session TS2 were "Mona Lisa" (Leonardo Da Vinci, 1519), "The birth of Venus" (Sandro Botticeli, 1486), Brunelleschi's dome of the Duomo of Florence, Santa Maria del Fiore (1436) and the Sistine Chapel ceiling frescoes (Michelangelo Buonarroti, 1512) (Fig. 1). AR was used to enhance the masterpiece images with information about art details relevant for the course. Added information was multimodal and included text, audio, video files and 3D models. Popcode, a markerless augmented reality tool was used to superimpose digital data to images of the masterpieces. Students explored freely augmented reality learning content in a laboratory room equipped with desktops and webcams.

\subsection{Research questions}

The purpose of this research study was to investigate the impact of two teaching scenarios: TS1 (based on slides) and TS2 (based on augmented reality technology) on student motivation. The study also included a qualitative analysis to determine the acceptability of AR technology among students. The research questions were:

1. Is there any difference in the students' motivation depending on which of the two teaching scenarios proposed they used?

2. Are there any differences in the four factors that measures student motivation depending on which of the two teaching scenarios proposed is used?

3. How motivated are students by using augmented reality teaching material?

4. Are there any difficulties or barriers that compromise the acceptability of AR technology in learning environments?

\subsection{Procedure}

Due to constraints imposed by the educational institution, it was not possible to separate students into two groups: an experimental group and a control group. Therefore, all the students participated in both learning scenarios and we applied a paired-sample analysis using paired $t$-tests. Quantitative data was collected in two steps. After the first part of the module (TS1), the motivational measurement instrument Instructional Materials Motivation Survey (IMMS) (Keller, 2010) was used to evaluate students' motivation. The same questionnaire was administered after students finished the second part of the module (TS2). Descriptive statistics were applied to summarize the answers on both surveys. All tests were conducted using a two-sided alpha level of 0.05 . The equality of population variances was checked before the use of any test that required this information. Finally, paired-sample $t$-tests were carried out to compare motivation between the two teaching scenarios.

The qualitative data was collected by observing students interacting with the augmented reality learning environment and conducting post-experience interviews.

\subsection{Participants}

In this study, sixty nine middle-school students (age $13-16, M=13.7, \mathrm{SD}=0.73$ ) from three sections of a public Spanish school were surveyed. A text document was provided to students and their parents outlining the purpose of the research and their right to withdraw at any moment. Informed consent was obtained for every participant. Among the respondents, 29 out 55 were female and 26 out of 55 were male. Only two participants declared having smart phones and previous contact with augmented reality technology.

\subsection{Instrument}

After obtaining permission from the author to use and modify the IMMS questionnaire, the instrument was slightly modified to adapt its terminology to the augmented reality field. IMMS contains 36 questions with 5-point Likert-scale items; this motivational measurement instrument is based on J.M. Keller's ARCS motivation model (Keller, 1987a,b). IMMS has a documented reliability coefficient of 0.96 (Keller, 2010) and has been administered in some research studies (Bolliger et al., 2010; Green \& Sulbaran, 2006; Rodgers \& Withrow-Thorton, 2005).

The qualitative data was collected looking for quality components of usability: learnability, efficiency, errors and satisfaction identified by Jakob Nielsen (Nielsen, 2003).
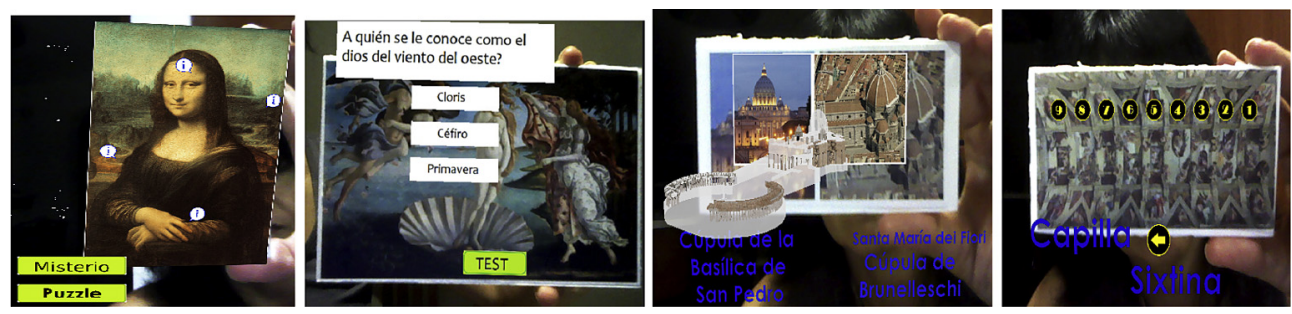

Fig. 1. Italian renaissance art images augmented with information, questions and 3D objects. 


\section{Results}

Sixty nine students participated in the research study. After the data collection phase, nine cases with missing data were deleted from the data. An exploratory data analysis revealed five outliers that were deleted. 29 out of 55 of the respondents were female. Participants' ages ranged from 13 to 16 with 48 out of 55 falling in the 13-14 year category.

\subsection{Research question 1}

Is there any difference in students' motivation depending on which of the two teaching scenarios proposed they used?

The minimum and maximum scores of the instrument IMMS are 36 and 180 since the response scale ranges from 1 to 5 . The total scores in TS1 ranged from 83 to 158 and the scores in TS2 ranged from 96 to 165 . These results indicate that students were moderately motivated when the module was taught within the slides-based learning environment and more motivated when it was taught within the augmented reality learning environment.

The Shapiro-Wilk test of normality distribution was used to examine the distribution of the difference in the motivation when the two teaching sceneries considered were used $(W=0.9748, p$-value $=0.299)$. Fig. 2 shows a normal $Q-Q$ plot of the difference in motivation. We can assume that the difference in motivation may come from a normal distribution (Shapiro \& Wilk, 1965). Therefore, parametric tests can be used for the rest of the analysis.

A paired-sample $t$-test was conducted to compare motivation. Result indicates a statistically significant difference in motivation between students following the course within TS2 $(M=3.616, \mathrm{SD}=0.499)$ and the same students following the course within TS1 ( $M=3.293$, $\mathrm{SD}=0.458), t(54)=4.1971, p=0.000$.

\subsection{Research question 2}

Are there any differences in the four factors that measures student motivation depending on which of the two teaching scenarios proposed is used?

Table 2 shows descriptive statistics for the four subscales used to describe motivation. For all subscales, the mean scores corresponding at TS2 are higher than those of TS1. Whereas all mean score subscales at TS1 are below 3.5, the attention, confidence and satisfaction subscales at TS2 are above 3.5. The highest differences among mean scores were yielded by the attention subscale $\left(M_{2}=3.76, M_{1}=3.28, M_{2}-\right.$ $\left.M_{1}=0.48\right)$ and satisfaction subscale $\left(M_{2}=3.51, M_{1}=3.11, M_{2}-M_{1}=0.40\right)$. The lowest difference was produced by the relevance subscale $\left(M_{2}=3.48, M_{1}=3.31, M_{2}-M_{1}=0.17\right)$.

For each of the four factors that describes motivation (Attention, Relevance, Confidence and Satisfaction) a Shapiro-Wilk test was performed to examine the difference when the two teaching scenarios were used. We conclude that the difference between each factor may come from a normal distribution: Attention $(W=0.9681, p$-value $=0.151)$, Relevance $(W=0.9617, p$-value $=0.078)$, Confidence $(W=0.9788, p$-value $=0.438)$ and Satisfaction $(W=0.9784, p$-value $=0.422)$. Paired-sample $t$-tests were conducted to compare the teaching scenarios over the four factors. Equality of population variances were tested for each factor and assumed to be equal. Results indicate that the difference between the two teaching scenarios was statistically significant in Attention $(t(54)=4.6629, p=0.000)$ and Satisfaction $(t(54)=3.9422, p$-value $=0.0002)$. Since we performed multiple tests of significance, the Bonferroni correction procedure was applied to prevent a chance of making a type I error. In both factors, the level of significance was confirmed.

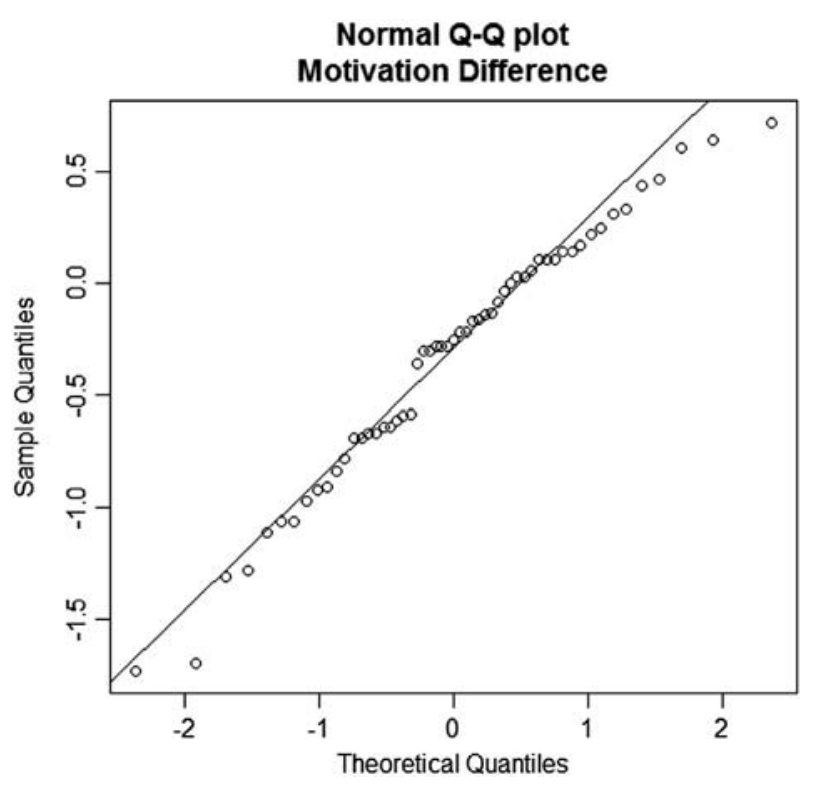

Fig. 2. Normal Q-Q plot. 
Table 2

Descriptive statistics for all subscales.

\begin{tabular}{lllll}
\hline Subscale & TS1 & & TS2 \\
\cline { 2 - 5 } & $M_{1}$ & $\mathrm{SD}_{1}$ & $M_{2}$ & 3.76 \\
\hline Attention & 3.28 & 0.55 & 3.48 & 0.72 \\
Relevance & 3.31 & 0.47 & 3.63 & 0.47 \\
Confidence & 3.4 & 0.53 & 3.51 & 0.57 \\
Satisfaction & 3.11 & 0.68 & 0.59 \\
\hline
\end{tabular}

\subsection{Research question 3}

How motivated are students by using augmented reality teaching material?

As it was previously stated (research question 1), students were highly motivated when using augmented reality teaching material. Indeed, data collected from IMMS survey revealed a mean score of 130.2 in a scale ranging between 96 and 165.

Table 1's two rightmost columns display descriptive statistics for the four subscales that describe motivation. The highest mean scores were yielded by the attention subscale $(M=3.76)$ and the confidence subscale $(M=3.63)$. The lowest mean value was obtained by the relevance factor $(M=3.48)$.

Table 3 shows the mean scores and standard deviations for each of the items that compose the attention factor. The highest mean score corresponds to item 8 which states that the augmented reality learning scenario was attention-grabbing for students. 43 out of 55 students thought that it was mostly true or very true that augmented reality technology was attention-grabbing. 41 out 55 of the respondents indicated that it was mostly true or very true that the way the information was arranged using this technology helped to keep their attention during the session (item 17). 40 out of 55 students responded that it was mostly true or very true that there was something interesting at the beginning of the augmented reality lesson that caught the students' attention (item 2).

Mean scores and standard deviations of the elements that describe the confidence are presented in Table 4.8 out of 55 participants indicated that it was mostly true or very true that the material was difficult to understand (item 3 ). 35 out of 55 students answered that it was mostly true or very true that the good organization of the material helped them feel confident that they would learn this lesson (item 35).

Table 5 shows the mean scores and standard deviations for items on the satisfaction subscale. The highest mean score was yielded by item 36 which states it was a pleasure to work on such a well designed lesson. 43 out of 55 participants indicated that it was mostly true or very true that it was a pleasure to work on such a well-designed lesson.

Finally, the lowest rated motivation factor is the relevance. Table 6 shows the mean scores and standard deviations for items on this subscale. None of the items had a mean score higher than 4.35 out of 55 participants indicated that it was mostly true or very true that the content and audio visual material in the lesson convey the impression that its content was important to know.

Regarding the items with the lowest mean scores (items 18 and 30), we can assert that the use of augmented reality technology is not the main cause of the low score. Only 16 out of 55 the participants reported that it was mostly true or very true that there were explanations or examples of how to use the knowledge in the lesson. 21 out of 55 participants indicated that it was true or very true that they could relate the content of the lesson to things they have seen, done, or thought about in their own life.

\subsection{Research question 4}

Are there any difficulties or barriers that compromise the acceptability of AR technology in learning environments?

For this research, we observed students to determine whether augmented reality, limited to desktops, could be used for middle-school classes. The criteria examined in this work included two areas of evaluation: learnability of the augmented reality system and efficiency on pursuing the learning tasks. Twenty four students were interviewed about their experience in using the system. The comments were related to difficulties found, satisfaction in the use of this technology and the impact that AR technology had in the learning process.

In the tutorial phase, the students were eager to learn the basic functionality of the learning tool. Whereas instructors conducted the tutorial on a group-by-group basis, the unattended students tried to use the learning system by themselves. We observed that close to twenty percent of the groups succeeded in this task, either by discovering how to operate the system by themselves or with the help of their peers. Students had no problems at all in learning how to interact with the different masterpieces presented and easily switched among the pictures. They quickly learned how to navigate through the information presented. From the very beginning of the experience, a collaboration nexus among students was established.

Students' comments show that learning to use the system was easy and enjoyable:

"Nice, it is so easy!"

"I find that it is really easy to use."

"It is just like a game."

The following situation was repeated several times with different students. A student observes that a peer is already using the application and asks for help:

"How did you achieve it?"

His/her peer answers:

"The picture has marks and when I click on them, I get information." 
Table 3

Mean scores and standard deviations of the attention items.

\begin{tabular}{|c|c|c|c|}
\hline & Item & $M$ & SD \\
\hline 2 & There was something interesting at the beginning of the AR lesson that caught my attention & 3.95 & 1.14 \\
\hline 8 & Augmented reality technology is attention-grabbing & 4.19 & 1.01 \\
\hline 11 & The quality of the augmented reality material helped to hold my attention & 3.88 & 1.05 \\
\hline 12 & The material is so abstract that it was hard to keep my attention on it (Reversed) & 3.72 & 1.28 \\
\hline 15 & The images, videos and text that I discovered through the lesson are unappealing (Reversed) & 3.77 & 1.34 \\
\hline 17 & The way the information is arranged using this technology helped keep my attention & 3.98 & 1.14 \\
\hline 20 & The information discovered through the experience stimulated my curiosity & 3.56 & 1.10 \\
\hline 22 & The amount of repetition of the activities made me feel bored (Reversed) & 3.54 & 1.38 \\
\hline 24 & I learned some things from the augmented reality that were surprising or unexpected & 3.46 & 1.13 \\
\hline 28 & The variety of audio visual material helped keep my attention on the lesson & 3.68 & 1.00 \\
\hline 29 & The audio visual material is boring (Reversed) & 3.88 & 1.25 \\
\hline 31 & There is so much content that it is irritating (Reversed) & 3.63 & 1.36 \\
\hline
\end{tabular}

Students finalized the exploration of all masterpieces in less time than expected. Two hours at the laboratory were enough to explore the information provided. Thus, students performed their learning activities efficiently. Spontaneously, some students began to review the information they found particularly interesting. We observed how in most of the groups, students continued being engaged in the activity by showing their peers the information they found more interesting or appealing. The exchange of views was centered on the artistic aspects of the masterpieces that students found relevant. For instance, we saw students arguing about the role of the nymph in "The Birth of Venus" and others comparing scenes from the Sistine Chapel. From the three sessions, only two students did not show interest in extra exploration. This situation contrasts with our observations after the TS1 session. Students did not comment about the masterpieces examined and gave few details about them when they were asked. When we asked some of them to reveal details of interest for them their answers were superficial with a low level of detail.

During the sessions, students had two kinds of technical problems with the images. Sometimes, it was hard to maintain the digital information visible superposed on the real image. Students mentioned that the problem was solved by changing the position of the real image in relation with the webcam. Once a group discovered how to fix the problem, they taught others and soon they stopped worrying about this. Thus, they soon continued with the learning activity. The second problem was related to shaking images and it was not possible to solve.

Examples of comments related with problems found:

"It is difficult to keep the picture in the right position."

"I notice that I have to maintain the picture centred but ... it is fine!"

"The image is shaking, this is a little bit annoying but ... I can continue."

"Sometimes, I lose the image. Nevertheless, it is easy to recover it."

Regarding the role of the AR technology on the learning process, students highlighted some advantages found:

"It helps me remember the information."

"I can concentrate better using this system than reading a book."

"I feel like I have been inside the picture."

"When I don't understand something, I can see or hear the information again."

"It was more fun than sitting in class, I did not feel bored."

"I like it better than the reading material or attending class."

"I prefer watching the videos than reading the text."

"I liked the 3D models."

Furthermore, for those students that claimed to have easily memorized the content, we asked them to describe the parts they liked most and they did it with a high detail level. In the interviews, students also said they were more confident about the knowledge acquired in this session than in the previous one.

Table 4

Mean scores and standard deviations of the confidence items.

\begin{tabular}{|c|c|c|c|}
\hline & Item & $M$ & SD \\
\hline 1 & When I first looked at the lesson, I had the impression that it would be easy for me & 3.67 & 1.12 \\
\hline 3 & This material was more difficult to understand than I would like for it to be (Reverse) & 4.11 & 1.19 \\
\hline 4 & After the introductory information, I felt confident that I knew what I was supposed to learn from this lesson & 3.21 & 0.88 \\
\hline 7 & The information that I was exploring was so much that it was hard to remember the important points (Reverse) & 3.68 & 1.27 \\
\hline 13 & As I worked on this lesson, I was confident that I could learn the content & 3.70 & 1.24 \\
\hline 19 & It was difficult to discover the digital information associated with the real image (Reverse) & 3.61 & 1.33 \\
\hline 25 & After working on this lesson for a while, I was confident that I would be able to pass a test on it & 3.44 & 1.07 \\
\hline 34 & I could not really understand quite a bit of the material in this lesson (Reverse) & 3.63 & 1.40 \\
\hline 35 & The good organization of the material helped me be confident that I would learn this material & 3.72 & 1.10 \\
\hline
\end{tabular}


Table 5

Mean scores and standard deviations of the satisfaction items.

\begin{tabular}{|c|c|c|c|}
\hline & Item & $M$ & SD \\
\hline 5 & Completing the exercises in this lesson gave me a satisfying feeling of accomplishment & 3.60 & 1.12 \\
\hline 14 & I enjoyed this lesson so much that I would like to know more about this topic & 3.26 & 1.03 \\
\hline 21 & I really enjoyed studying this lesson & 3.53 & 1.07 \\
\hline 27 & The wording of feedback after the exercises, or of other comments in this lesson, helped me feel rewarded for my effort & 3.11 & 1.06 \\
\hline 32 & It felt good to successfully complete this lesson & 3.63 & 1.06 \\
\hline 36 & It was a pleasure to work on such a well-designed lesson & 4.14 & 0.88 \\
\hline
\end{tabular}

"I can tell you all that's happening in "The birth of Venus" and what the role of each character is."

"I know why Monalisa's smile is so interesting."

"I understood this lecture better than the previous one."

Finally, students expressed their satisfaction with the learning experience, their willingness to participate in similar tasks and showed interest in installing the application on their phones. A student even wanted to learn how to develop these kinds of applications in his mobile phone. We reproduce some of their comments:

"This activity is entertaining."

"It is better than reading the book; I would like to have it (the application) in other courses."

"May I have this in my phone?" "How did you do it? Can I do it by myself?"

\section{Discussion}

\subsection{Considerations about how the study was conducted}

Due to constraints imposed by the school, the study was performed with no control group. Instead the same motivational instrument was applied twice to the same group of students in order to evaluate both scenarios. The appropriate statistical methods were used to analyze the results. Both sessions followed the same pedagogical structure and students received similar learning contents. In what follows we analyze some considerations regarding content and delivery of the course material in order to identify any factor related to the deployment of the study that could favor TS2 over TS1.

- The attention motivation factor reflects the interest of learners toward the activity performed. The sessions were deployed using the same content of previous editions of the course and it was evenly distributed between the sessions. Thus, neither the content nor the order of sessions could be an important disturbing factor on results. On the other side, an AR based learning environment has a technical advantage over the TS1 in terms of grasping the attention of students, the content can be multimodal and students could interact with it. Indeed, both quantitative and qualitative data showed that these special characteristics of AR technology had indeed an impact on students' motivation.

- The ARCS confidence factor intends to measure the feeling of control and expectancy for success. From the qualitative study we noticed that students were pleased to freely explore the learning contents at TS2, they did not have that possibility at TS1. Thus, neither the content, nor the order of sessions could have a significant impact on results. On the other hand, due to the fact that the expectancy for success is linked to module's assessment, there is a risk of confusion among the answers of both sessions. Even if students said they were more confident about what they have learnt in TS2 than in TS1, their opinions may have favored the results for AR because it is easier to remember what has just happened.

- The satisfaction factor could have been more favorable for TS1 than for TS2. Nevertheless, whereas students were familiar with TS1, TS2 represented a new learning environment based on the use of an unknown technology. Fortunately, the usability study proved that students did not have any difficulty with the new technology. Further studies are necessary to determine whether the novelty factor could have a significant impact on the results.

- The relevance factor deals with how well the course meets a learner's needs and goals. The course material was similar in both sessions and neither quantitative data nor students' comments suggest significant changes in their motivation.

Table 6

Mean scores and standard deviations of the relevance items.

\begin{tabular}{|c|c|c|c|}
\hline & Item & M & SD \\
\hline 6 & It is clear to me how the content of this material is related to things I already know & 3.68 & 1.10 \\
\hline 9 & There were images, videos and texts that showed me how this material could be important to some people & 3.58 & 1.13 \\
\hline 10 & Completing this lesson successfully was important to me & 3.54 & 0.89 \\
\hline 16 & The content of this material is relevant to my interests & 3.44 & 0.96 \\
\hline 18 & There are explanations or examples of how people use the knowledge in this lesson & 3.02 & 1.04 \\
\hline 23 & The content and the audio visual material in this lesson convey the impression that its content is worth knowing & 3.79 & 0.96 \\
\hline 26 & This lesson was not relevant to my needs because I already knew most of it (Reversed) & 3.70 & 1.15 \\
\hline 30 & I could relate the content of this lesson to things I have seen, done, or thought about in my own life & 3.14 & 1.06 \\
\hline 33 & The content of this lesson will be useful to me & 3.54 & 1.02 \\
\hline
\end{tabular}




\subsection{Differences on learner's motivation by the use of two teaching scenarios}

The result obtained when we compare both scenarios using a paired-sample $t$ test indicates that there is a statistically significant difference. The mean scores obtained were $M_{\mathrm{TS} 2}=3.616$ and $M_{\mathrm{TS} 1}=3.293$ respectively. Thus, students were moderately motivated by the traditional way of teaching the course and slightly more motivated when augmented reality technology was used.

$M_{\mathrm{TS} 2}$ and $M_{\mathrm{TS} 1}$ summarize four motivational factors; in our case it is worth analyzing the mean scores of the subscales to determine the impact of support technology on each of the four factors. The mean rates' difference becomes bigger when comparing attention $\left(M_{\mathrm{TS} 1}=3.28\right.$, $\left.M_{\mathrm{TS} 2}=3.76\right)$ and satisfaction $\left(M_{\mathrm{TS} 1}=3.11, M_{\mathrm{TS} 2}=3.51\right)$ motivation factors. The positive impact of AR technology on students' attention is an encouraging result in the education arena. Indeed, it is one of the educational affordances that is expected from emerging technologies such as 3D virtual worlds and augmented reality (Dalgarno \& Lee, 2010; Dickey, 2005). Better participants' satisfaction perception could be tied to their active participation in exploring information that is a consequence of the interactive possibilities of AR technology.

The study also demonstrates that the relevance factor remained almost unchanged in both learning scenarios. Thus students' interest for the subject was not modified by AR technology.

\subsection{Learner's motivation by the use of augmented reality technology in their courses}

The results show that participants were motivated by the use of augmented reality technology when it was integrated into their learning environments. The attention $(M=3.76)$ and the confidence $(M=3.63)$ factors received the highest ratings of the four subscales. Results suggest that education based on augmented reality could assist us in gaining and holding the attention of learners. It is important to note that five out of twelve statements on the attention subscale exceeded a mean score of 3.8. In addition, the confidence factor related to participants' feelings of personal control and expectancy for success can influence their learning efforts. Five out of nine items on the confidence factor exceeded a mean score of 3.65. In general, participants were confident that they were able to understand and follow the learning content.

In terms of the attention and confidence levels, our results are similar to those presented by D.U. Bolliger et al. (Bolliger et al., 2010) in their study about the impact of podcasting on student motivation in the online learning environment that also uses the IMMS questionnaire. However, there is a slight difference, D.U. Bolliger et al. found that confidence received higher ratings than attention $(M=3.76$ and $M=3.61$ respectively). It is worth to notice that these mean values are very similar to ours.

Regarding the satisfaction factor, results show that students were satisfied with the use of augmented reality technology to support the learning environment. The term satisfaction is defined either as the fulfillment of a need or wants (items 5, 32 and 36) with mean scores above 3.6, or as source of enjoyment (items 14 and 27) with mean scores of 3.26 and 3.53 respectively. Besides, in our study, the relevance subscale received the lowest mean score $(M=3.48)$ with five out nine items below 3.55. These results suggest that students were pleased to fulfill an academic requirement even though their needs were not aligned with course objectives.

The lowest items in all IMMS questionnaire are items 18 and 27 with mean scores $M=3.02$ and $M=3.11$ respectively. The former inquires about the existence of examples showing how to use the knowledge of the lesson, the latter asks about the student's perception of appropriate feedback. In both cases the drawback can be overcome with a better design of the learning experience.

\subsection{Feasibility of using augmented reality technology in middle-school education}

From the usability study, it can be concluded that students learned with no difficulty how to use the augmented reality learning system. They successfully and timely completed the tasks assigned.

Technical problems found were not serious enough to diminish the enthusiasm of students to accomplish the learning activities supported by augmented reality technology.

\subsection{Benefits of using AR technology in learning}

During the sessions, students showed high levels of engagement and enjoyment and the AR learning environment was repeatedly described as appealing. Students expressed their satisfaction in terms of material used, the possibility of receiving information in different formats, and the feeling of having control of the activity as they could explore the topics in the order they chose and could revisit materials as needed.

Several students reported they achieved high levels of concentration while performing tasks. They also claimed that had managed to memorize the learning content easily. Indeed, once the exploration activity had finished, students spontaneously formed discussion groups where each one described and analyzed in detail parts of the material they found particularly interesting.

\section{Conclusions and future work}

The quantitative results of this research study showed that the use of augmented reality technology on learning environments had a positive effect on the motivation of middle-school students. The effect has been analyzed in isolation and in comparison with traditional course lectures. The motivation mean scores obtained were $M=3.62$ for the augmented reality based learning scenario and $M=3.29$ for the course based on slides. A clear improvement on the attention and the satisfaction motivation factors for the learning environment based on augmented reality technology compared with a more traditional learning environment was noticed. These results were supported by a qualitative study where students claimed that an AR learning environment was more appealing and easy to understand than the slidebased course. It was not surprising to find that the relevance motivation factor remained almost the same for both learning environments. Technology is not the panacea for education; students demand content aligned to their interests.

When the measures of the quantitative analysis were analyzed in isolation, the attention and confidence factors were the highest rated motivation factors with mean scores of $M=3.76$ and $M=3.63$ respectively. The results for satisfaction $(M=3.51)$ and relevance $(M=3.48)$ 
were also encouraging. Thus, the quantitative analysis proved that learners were moderately motivated with the use of augmented reality technology. These results were completed with a qualitative analysis that provides clues about the benefits of AR in the teaching-learning process.

Relevant affordances of AR technology for learnings such as enhancement of concentration and memorizing were detected during the qualitative analysis of TS2 session. We observed that after the TS2 session, students were able to describe and analyze the learning content with a higher level of detail than after the TS1 session. We believe that the immersive capabilities of AR helped students maintain higher levels of attention and interest on the learning content. The higher concentration and memorization levels that students claimed to achieve with AR technology, seems to cause this positive effect on learning outcomes. Further studies should be conducted to validate this conclusion.

At TS2, students remarked as positive to have control of the exploration of the material and the possibility to receive multimodal information. This gives us clues about the differences found in motivation in both teaching scenarios. Students at TS1 could only interact with the learning material through their teacher. Due to its navigability possibilities, AR allows the deployment of learner-centered activities more easily. On the other hand, multimodal information helps to break monotony and to deal with different learning styles. In this regard also, AR technology is a valuable supporter for learning.

A favorable factor for social learning was the discussion groups formed about the learning content explored. When comparing the attitude of students after the two sessions evaluated we noticed a desire to share their experiences of TS2 but not in TS1. We believe that the difference is mainly due to the satisfaction produced on using AR technology but further studies should be done to confirm this hypothesis.

In relation with the usability study, authors were greatly surprised to observe how students were able to quickly learn and use the augmented reality system and the ease with which students overcame the technical problems that arose. Students manifested their interest in continuing using this technology in other courses and at home. Thus, although AR is not mature enough to be used massively in education, enthusiasm of middle-school students diminished most of the barriers found.

As a result of our study, we conclude that the positive impact of AR on motivation leads students to achieve higher levels of engagement in learning activities with less cognitive effort.

Finally, although these are encouraging results, it is advisable to deploy similar research studies in extended periods of time to diminish the novelty effect that can be acting as a disturbing factor. It could be also useful to determine the learning activities where AR technology can provide greater benefits.

\section{Acknowledgements}

The authors are deeply grateful to professors and students from I.E.S. Enrique Tierno Galván at Madrid (Spain) that gently collaborated on this research study. The authors also wish to thank Dr. John Keller for his permission to use and modify the Instructional Materials Motivation Survey in this research study. This research has been partially supported by the Spanish national projects Learn3 (grant TIN200805163/TSI) and EEE (grant TIN2011-28308-C03-01) and the Madrid regional project eMadrid (grant S2009/TIC-1650).

\section{References}

Annetta, L. A., Minogue, J., Holmes, S. Y., \& Cheng, M.-T. (2009). Investigating the impact of video games on high school students' engagement and learning about genetics. Computers \& Education, 53(1), 74-85, Elsevier Ltd.

Azuma, R. T. (1997). A survey of augmented reality. In Presence: Teleoperators and Virtual Environments, 6, 355-385.

Azuma, R., Baillot, Y., Behringer, R., Feiner, S., Julier, S., \& MacIntyre, B. (2001). Recent advances in augmented reality. IEEE Computer Graphics and Applications, 21(6), 34-47, IEEE Computer Society.

Barab, S., Thomas, M., Dodge, T., Carteaux, R., \& Tuzun, H. (2005). Making learning fun: Quest Atlantis, A game without guns. Educational Research E Development, 53(1), 86-107.

Barger, A., \& Byrd, K. (2011). Motivation and computer-based instructional design. Journal of Cross-Disciplinary Perspectives in Education, 4(1), 1-9.

Billinghurst, M., Kato, H., \& Poupyrew, L. (2001). The MagicBook: moving seamlessly between reality and virtuality. IEEE Computer Graphics and Applications, 2-4.

Bolliger, D. U., Supanakorn, S., \& Boggs, C. (2010). Impact of podcasting on student motivation in the online learning environment. Computers E Education, 55(2), 714-722, Elsevier Ltd.

Bower, M. (2008). Affordance analysis - matching learning tasks with learning technologies. Educational Media International, 45(1), 3-15, Routledge.

Burigat, S., \& Chittaro, L. (2007). Navigation in 3D virtual environments: effects of user experience and location-pointing navigation aids. International Journal of HumanComputer Studies, 65(11), 945-958, Elsevier.

Carmigniani, J., Furht, B., Anisetti, M., Ceravolo, P., Damiani, E., \& Ivkovic, M. (2010). Augmented reality technologies, systems and applications. Multimedia Tools and Applications, 51(1), 341-377, Springer Netherlands.

Chien, C. -Huan, Chen, C.- Hsu, \& Jeng, T.- Sheng. (2010). An interactive augmented reality system for learning anatomy structure. Computer, I. IAENG.

Chittaro, L., \& Ranon, R. (2007). Web3D technologies in learning, education and training: motivations, issues, opportunities. Computers \& Education, 49(1), 3-18, Elsevier.

Csikszentmihalyi, M. (1991). Flow: The psychology of optimal experience. Harper Perennial.

Dünser, A., Steinbügl, K., Kaufmann, H., \& Glück, J. (2006). Virtual and augmented reality as spatial ability training tools. In Proceedings of the seventh ACM SIGCHI New Zealand chapter's international conference on computer-human interaction (pp. 125-132).

Dalgarno, B. (2004). A classification scheme for learner-computer interaction. In Annual conference of the Australasian society for computers in learning in tertiary education (pp. $240-248)$.

Dalgarno, B., \& Lee, M. J. W. (2010). What are the learning affordances of 3-D virtual environments? British Journal of Educational Technology, 41(1), 10-32, Blackwell Publishing Ltd.

Dickey, M. D. (2005). Brave new (interactive) worlds: a review of the design affordances and constraints of two 3D virtual worlds as interactive learning environments. Interactive Learning Environments, 13(1-2), 121-137, Routledge.

Driscoll, M. P. (2000). Introduction to theories of learning instruction. Psychology of learning for instruction (2nd ed.). Boston: Allyn and Bacon.

Dror, I. (2008). Technology enhanced learning: the good, the bad, and the ugly. Pragmatics Cognition, 2(2), 215-223, John Benjamins Publishing Company.

Dunleavy, M., Dede, C., \& Mitchell, R. (2009). Affordances and limitations of immersive participatory augmented reality simulations for teaching and learning. Journal of Science Education and Technology, 18(1), 7-22, Springer Netherlands.

Efklides, A., Kuhl, J., \& Sorrentino, R. M. (2001). Trends and prospects in motivation research. Dordrecht; Boston; London: Kluwer Academia.

Green, M., \& Sulbaran, T. (2006). Motivation assessment instrument for virtual reality scheduling simulator. In T. Reeves, \& S. Yamashita (Eds.), Proceedings of world conference on e-learning in corporate, government, healthcare, and higher education 2006 (pp. 45-59). Chesapeake, VA: AACE.

Gutiérrez, M. J., Saorín, J. L., Contero, M., Alcañiz, M., López, P. D. C., \& Ortega, M. (2010). Design and validation of an augmented book for spatial abilities development in engineering students. Computers E Graphics, 34(1), 77-91.

Henderson, S., \& Feiner, S. (2011). Exploring the benefits of augmented reality documentation for maintenance and repair. IEEE Transactions on Visualization and Computer Graphics, 17(10), 1355-1368. 
Huang, D. W., Diefes-Dux, H., Imbrie, P. K., Daku, B., \& Kallimani, J. G. (2004). Learning motivation evaluation for a computer-based instructional tutorial using ARCS model of motivational design. In 34th ASEE/IEEE frontiers in education conference T1E.

Huang, H.-M., Rauch, U., \& Liaw, S.-S. (2010). Investigating learners' attitudes toward virtual reality learning environments: based on a constructivist approach. Computers $\mathcal{E}$ Education, 55(3), 1171-1182, Elsevier Ltd.

Huitt, W. (2011). Motivation to learn: an overview. Educational Psychology Interactive. Valdosta, GA: Valdosta State University. Retrieved from http://www.edpsycinteractive. org/topics/motivation/motivate.html.

Jeamu, L., Kim, Y., \& Lee, Y. (2008). A web-based program to motivate underachievers learning number sense. International Journal of Instructional Media, 35(2), 185-194.

Jonassen, D. H. (1994). Technology as cognitive tools: learners as designers. ITForum Paper, 1,1-7, Retrieved from. http://aurorem.free.fr/partiels/sem7/cours/textesprincipaux/ ITForum_Paper1_jonassen.pdf.

Keller, J. M. (1979). Motivation and instructional design: a theoretical perspective. Journal of Instructional Development, 2, 26-34

Keller, J. M. (1987a). Development and use of the ARCS model of motivational design. Journal of Instructional Development, 10(3), 2-10.

Keller, J. M. (1987b). Strategies for stimulating the motivation to learn. Performance and Instruction, 26(8), 1-7.

Keller, J. M. (2008). An integrative theory of motivation, volition, and performance. Technology Instruction Cognition and Learning, 6(2), 79-104.

Keller, J. M. (2010). Motivational design for learning and performance. Science + Business Media227-286, Springer.

Keller, J. M., \& Litchfield, B. C. (2002). Motivation and performance. In R. A. Reiser, \& J. V. Dempsey (Eds.), Trends and issues in instructional design and technology. New Jersey: Merill Prenctice Hall.

Kleinginna, P. R., \& Kleinginna, A. M. (1981). A categorized list of motivation definitions, with a suggestion for a consensual definition. Motivation and Emotion, 5(3), 263-291, Springer.

Klopfer, E., \& Squire, K. (2008). Environmental Detectives-the development of an augmented reality platform for environmental simulations. Educational Technology Research E Development, 56(2), 203-228, Springer.

Krevelen, D. W. F. V., \& Poelman, R. (2010). A survey of augmented reality technologies, applications and limitations. The International Journal of Virtual Reality, 9(2), 1-20.

Kulik, J. A. (1994). Meta-analytic studies of findings on computer-based instruction. In E. L. Baker, \& H. F. O’Neill, Jr. (Eds.), Technology assessment in education and training (pp. 9-33). Lawrence Erlbaum.

Kye, B., \& Kim, Y. (2008). Investigation of the relationships between media characteristics, presence, flow, and learning effects in augmented reality based learning augmented reality. International Journal, 2(1), 4-14.

Lombard, M., \& Ditton, T. (1997). At the heart of it all: the concept of presence. Journal of Computer-Mediated Communication, 3(2), 20, Wiley Online Library.

Maier, P., Tönnis, M., \& Klinker, G. (2009). Dynamics in tangible chemical reactions. World Academy of Science Engineering and Technology, $57,80-87$.

Milgram, P., \& Kishino, A. F. (1994). Taxonomy of mixed reality visual displays. IEICE Transactions on Information and Systems, E77-D(12), 1321-1329.

Moore, M. G. (1989). Three types of interaction. The American Journal of Distance Education, 3(2), 1-6.

Narzt, W., Pomberger, G., Ferscha, A., Kolb, D., Müller, R., Wieghardt, J., et al. (2005). Augmented reality navigation systems. Universal Access in the Information Society, 4(3), 177-187, Springer-Verlag.

Nejdl, W., Tochtermann, K., Bogen, M., Wind, J. \&Giuliano, A. (2006). ARISE - Augmented Reality in School Environments. In Nejdl, W., Tochtermann, K. (eds.), pp. 709-714. Springer.

Neumann, U., \& Majoros, A. (1998). Cognitive, performance, and systems issues for augmented reality applications in manufacturing and maintenance. In Proceedings IEEE 1998 virtual reality annual international symposium Cat No98CB36180 (pp. 4-11). IEEE Comput. Soc.

Nielsen, J. (2003). Usability 101: Introduction to usability, Jakob Nielsen's Alertbox. Retrieved 2011-07-25. http://www.useit.com/alertbox/20030825.html.

Nilsson, S., Johansson, B. J. E., \& Jönsson, A. (2010). Cross-organisational collaboration supported by augmented reality. IEEE Transactions on Visualization and Computer Graphics, $17(\mathrm{X})$.

Perry, R. P. (1991). Perceived control in the collage classroom. InSmart, J. C. (Ed.). (1991). Higher education handbook of theory and research, Vol. 7. New York: Agathon.

Pintrich, P. (1999). The role of motivation in promoting and sustaining self-regulated learning. International Journal of Educational Research, 31(6), 459-470, Elsevier.

Pintrich, P. R., \& De Groot, E. V. (1990). Motivational and self-regulated learning components of classroom academic performance. Journal of Educational Psychology, 82(1), 3340, American Psychological Association.

Platonov, J., Heibel, H., Meier, P., \& Grollmann, B. (2006). A mobile markerless AR system for maintenance and repair. In 2006 IEEE-ACM international symposium on mixed and augmented reality (pp. 105-108). IEEE.

Raffini, J. (1993). Winners without losers: Structures and strategies for increasing student motivation to learn. Allyn \& Bacon Publishers.

Rodgers, D. L., \& Withrow-Thorton, B. J. (2005). The effect of instructional media on learner motivation. International Journal of Sport Psychology, 32, 91-106.

Rost, M. (2010). Generating student motivation [Internet]. WorldView, Pearson Longman. Available from $<$ http://www.pearsonlongman.com/ae/worldview/> Accessed 25.08.11.

Rovai, A. P., Ponton, M. K., Wighting, M. J., \& Baker, J. D. (2007). A comparative analysis of student motivation in traditional classroom and E-learning courses. International Journal on E-Learning, 6(3), 413-432.

Schacter, J. (1999). The impact of education technology on student achievement. In What the most current research has to Say San Francisco Milken exchange. Milken Exchange on Education Technology.

Schmidt, J. T. (2007). Preparing students for success in blended learning environments: future oriented motivation \& self-regulation. Educational Research, 301-302.

Shapiro, S. S., \& Wilk, M. B. (1965). An analysis of variance test for normality (complete samples). Biometrika, 52(3-4), 591-611.

Shen, J. \& Eder, L. B. (2009). Intentions to use virtual worlds for education. Journal of Information System Education, 20(2), 225-233.

Sherman, W. R., \& Craig, A. B. (2003). Understanding virtual reality. New York: Morgan Kaufmann Publishers.

Sivin-Kachala, J. (1998). Report on the effectiveness of technology in schools, 1990-1997. Software Publisher's Association.

Specht, M., Ternier, S., \& Greller, W. (2011). Dimensions of mobile augmented reality for learning: a first inventory. Journal of the Research Center for Educational Technology, $7(1), 117-127$.

Stipek, D. (1998). Motivation to learn: From theory to practice, Vol. 4. Allyn and Bacon.

Sumadio, D. D., \& Rambli, D. R. A. (2010). Preliminary evaluation on user acceptance of the augmented reality use for education. In. 2010 second international conference on computer engineering and applications, Vol. 2 (pp. 461-465).

Svinicki, M. (1999). New directions in learning and motivation. In M. D. Svinicki (Ed.), Teaching and learning on the edge of the millennium: Building on what we have learned. New directions for teaching and learning, Vol. 80. San Francisco: Jossey-Bass.

Taran, C. (2005). Motivation techniques in elearning, ICALT 2005. In Fifth IEEE international conference on advanced learning technologies (pp. 617-619).

Theall, M. (1999a). Motivation from within: encouraging faculty and students to excel. New Directions for Teaching and Learning, N. 78. San Francisco: Jossey-Bass.

Theall, M. (1999b). New directions for theory and research on teaching: a review of the past twenty years (80). New Directions for Teaching and Learning29-52, San Francisco: Jossey-Bass.

Vianin, P. (2006). La motivation scolaire: Comment susciter le désir d'apprendre ? Bruxelles: De Boeck \& Larcier, Editions De Boeck Universite.

Wlodkowski, R. J. (1978). Motivation and teaching: A practical guide. National Education Association.

Zimmerman, B. J., Bandura, A., \& Martinez-Pons, M. (1992). Self-motivation for academic attainment: the role of self-efficacy beliefs and personal goal Setting. American Educational Research Journal, 29(3), 663-676. 